\title{
Time spent close to a sexual partner as a measure of female mate preference in a sex-role-reversed population of the blenny Salaria pavo (Risso) (Pisces: Blenniidae)
}

Received: 16 January 2003 / Revised: 5 March 2003 / Accepted: 14 March 2003 / Published online: 18 September 2003 (C) Springer-Verlag and ISPA 2003

\begin{abstract}
In most species females do not exhibit conspicuous sexual behaviours and female mate preferences are often measured by means of the time spent close to males. In spite of its widespread use, in only a few studies has this measure been validated as a reliable indicator of female mate preference. Sex-role-reversed species offer a better opportunity to test female preferences, as females usually court males. We tested in a sex-role-reversed population of the blenny Salaria pavo (Risso) if the time spent by females close to males related to the number of courtship displays directed towards males, and whether these measures of female preference reliably predicted matings. Females were simultaneously presented with two males behind a glass partition and the time spent close to each male was measured. We then allowed females to have access to the males' compartments and measured the courtship behaviours performed by females towards each male and recorded with which of the males females spawned. Females spent more time close to the male that subsequently received more courtship displays, and the preferred male had a more developed head crest. However, both measures of female preference failed to predict matings. Females were often attacked by males and probably had, in some occasions, to spawn with the less preferred male. Females that spawned with the previously preferred male had more swollen bellies than females that spawned with the less preferred male, suggesting a male preference towards more ripe females. These results validate the use of "time spent close to a sexual partner" as a measure of female preference in $S$. pavo. We argue that matings may not always reliably indicate mate preferences, particularly in the less choosy sex.
\end{abstract}

Communicated by R. Serrão Santos

D. M. Gonçalves $(\varangle) \cdot$ R. F. Oliveira

Unidade de Investigação em Eco-Etologia,

Instituto Superior de Psicologia Aplicada,

Rua Jardim do Tabaco 34, 1149-041 Lisbon, Portugal

e-mail: davidg@ispa.pt

Tel.: +351-21-8811700

Fax: $+351-21-8860954$
Keywords Female preference $\cdot$ Mate choice $\cdot$ Sexual selection · Sex-role reversed - Salaria pavo

\section{Introduction}

In most animal species sexual selection acts more strongly on males, and as a consequence, males usually have more elaborated secondary sex traits and display more complex courtship behaviours (Darwin 1859, 1871; Andersson 1994). Female preferences for specific male traits are, in part, responsible for the mating pattern occurring in a population (Jennions and Petrie 1997). Females usually do not exhibit conspicuous courtship displays and previous studies have relied on the time spent by females near the male as a measure of female preference (e.g. Basolo 1990; Milinski and Baker 1990; Kodric-Brown and Nicoletto 1997; Landmann et al. 1999).

Although in sex-role-reversed species females are the less choosy sex, the active courtship behaviours displayed towards males (e.g. the pipefish Syngnathus typhle L., Berglund et al. 1986; the Banggai cardinal fish Pterapogon kauderni Koumans, Vagelli 1999) offer a better opportunity to study female mate preferences. Courtship behaviours directed towards males are likely to be a good indicator of female propensity to mate with a particular male, although actual matings also depend on other factors such as costs associated with mate searching and male choosiness (Jennions and Petrie 1997). In these species it is possible to evaluate if the time spent close to a male correlates with more direct measures of female preference, such as courtship behaviours directed towards the male, and how these preferences influence the mating pattern. Time spent close to a sexual partner is an easy-tomeasure and unambiguous variable and it constitutes a valuable tool if it can be demonstrated that it reliably indicates female preferences.

In spite of the widespread use of this variable as a measure of female preference, studies validating its application are scarce. Ideally, an association between the time spent close to the male with matings or with 
other measures of female preference must be shown. In fish it has been validated, for example, for the cichlid Pseudotropheus (Metriaclima) zebra (Boulenger) (Couldridge and Alexander 2001), the guppy Poecilia reticulata Peters (Kodric-Brown 1985), the swordtail Xiphophorus nigrensis Rosen (Ryan et al. 1990), the sailfin molly Poecilia latipinna (Lesueur) (Schlupp et al. 1994), the pipefish Nerophis ophidion (L.) (Rosenqvist 1990) and the sand goby Pomatoschistus minutus (Pallas) (Forsgren 1992).

We investigated in a Portuguese population of the peacock blenny, Salaria pavo (Risso), where sex-role reversal occurs, if the time previously spent by females close to males was correlated with another measure of female preference and whether these measures of preference were good predictors of matings.

$S$. pavo is an intertidal fish from the temperate Mediterranean and Atlantic coasts (Zander 1986). It exhibits a strong sexual dimorphism with males being larger than females, having a well-developed head crest and an anal gland in the first two rays of the anal fin (Papaconstantinou 1979; Patzner et al. 1986; Patzner and Seiwald 1987). Males defend nests in crevices or holes and take care of the eggs (Patzner et al. 1986). Females may lay eggs with several males throughout the breeding season and the same male may receive eggs from more than one female (Patzner et al. 1986).

In Portugal, a population of $S$. pavo occurs in an area where there is a scarcity of appropriate nest sites. Males compete strongly for the access to nests and do not defend any territory around the nest (Almada et al. 1994). At the peak of the breeding season most nests are fully covered with eggs and females have to compete for potential mates (Almada et al. 1994). This leads to a female-biased operational sex ratio and, unlike in other Mediterranean populations (Fishelson 1963), the sex roles are reversed, with females being the courting sex (Almada et al. 1995). Females approach males, adopting a typical nuptial colouration and beating the pectoral fins rapidly with synchronized opercula movements (Almada et al. 1995), while males usually adopt a more or less passive role.

Unlike the generality of sex-role-reversed species, in this population males have secondary sex traits more developed than females. Although it is still not clear why this happens, it should be noted that this is an atypical population of the species, with the sex roles reversed due to ecological constraints (Almada et al. 1995). Males still have the ability to court females when placed in an environment with an excess of nest sites, reflecting behavioural plasticity of courtship behaviour (Almada et al. 1995).

The conspicuous courtship display exhibited by females, together with the well-developed male secondary sex traits, makes this population of $S$. pavo ideal to study female sexual preferences. In this study it was tested if time previously spent by females close to males correlated with female courtship behaviour and whether these measures of preference were good predictors of matings.

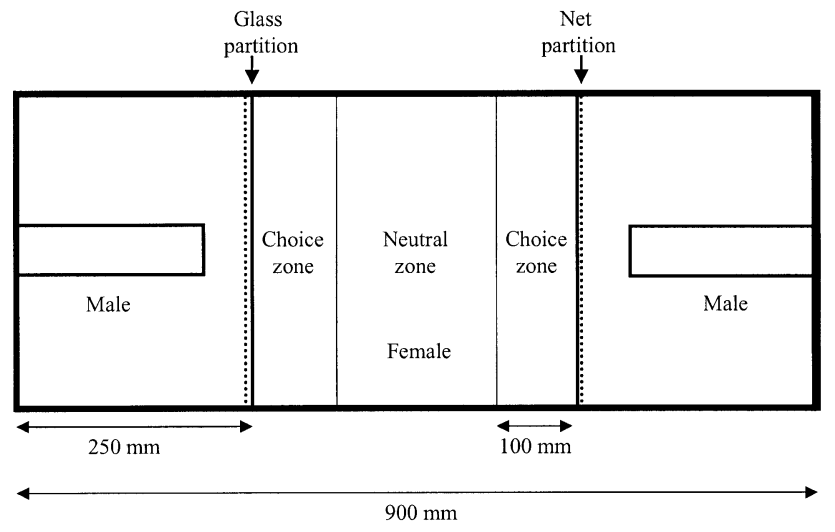

Fig. 1 Top view of the experimental set-up

\section{Methods}

Fish

All animals were captured in the Ria Formosa Nature Park (south Portugal, Algarve, $36^{\circ} 59^{\prime} \mathrm{N}, 7^{\circ} 51^{\prime} \mathrm{W}$ ). Only males guarding nests with eggs in the field and ripe females (recognized on the basis of a distended belly) were used in the experiment, which was performed during the species breeding season (June/July). Males and females were kept in two separate stock tanks of $80 \times 35 \times 30 \mathrm{~cm}$, bottoms covered with a layer of sand and provided with artificial nests. The tanks were illuminated by fluorescent lamps on a $16 \mathrm{~h}: 8 \mathrm{~h}$ light:dark cycle. Salinity was kept at $35 \%$ and temperature varied between 20 and $25^{\circ} \mathrm{C}$. The animals were fed daily with frozen common cockles (Cerastoderma sp.). Experiments were performed 2 days after fish capture. No mortality occurred during captivity and all animals were released in the same place where they were captured.

\section{Choice tests}

The experimental tank $(90 \times 35 \times 40 \mathrm{~cm})$ was divided into three different compartments by glass and a rigid net (Fig. 1). The bottom was covered with a layer of sand and the set-up was illuminated by two 30-W fluorescent lamps placed $20 \mathrm{~cm}$ above water level. During choice trials one male was placed into each of the outer compartments; an opaque glass box of $21 \times 5 \times 5.5 \mathrm{~cm}$ with an opening of $2.5 \times 2.5 \mathrm{~cm}$ turned to the central compartment provided an artificial nest for males. The central compartment was divided by lines drawn on the front and back walls into two choice zones, adjacent to each of the male's compartments, and one neutral zone (Fig. 1). Two hours before trials males were placed in the end compartments and a female was released in the central compartment to acclimate to the experimental tank. During acclimation two opaque plates limited the female to the neutral zone and provided a visual barrier between the female and the males. All males adopted the provided nest and typically spent most of the time inside the nest with the head out, which is also the most common position observed in the field. Choice trials were divided into two steps: (1) after acclimation the opaque plates were removed and the female's behaviour and position were video recorded for $20 \mathrm{~min}$. After this period the males' sides were switched and the female was again restricted to the neutral area by the opaque plates for $10 \mathrm{~min}$; (2) the glass barriers separating the males' compartments from the central compartment were removed and only the rigid nets were left between these compartments. The opaque plates were removed and a second observational period of $20 \mathrm{~min}$ was video recorded.

The nets had square openings of $1 \times 1 \mathrm{~cm}$ and, because in this species males are significantly larger than females, females were able to pass through the nets while males were not. This procedure 
prevented physical contact between males, which could have influenced the female choice, and allowed access to both nests by the female. The fish were left in the tank for the next 2 days and both nests were checked for eggs every $3 \mathrm{~h}$ during the day.

The frequency of female courtship behaviours directed towards each male and the time spent in each of the choice zones were quantified from videotapes using Observer PC software V3.0 (Noldus Information Technology, Wageningen, The Netherlands). We had previously defined that if one of the males spent more than $50 \%$ of the time completely inside the nest (not visible to the female being tested) in any of the observational periods the trial would be aborted. However, this situation never occurred.

A total of 20 females (standard length, SL, mean \pm $\mathrm{SE}=6.1 \pm 0.16 \mathrm{~cm})$ and 40 males $(\mathrm{SL}$, mean $\pm \mathrm{SE}=9.8 \pm 0.18 \mathrm{~cm})$ were used in the experiment, and no fish was used more than once. Before experiments the standard length of all animals was measured. In males the development of the anal gland was classified on an ordinal scale of 0 to 3 and the head height (including the crest) and body height were measured to calculate a relative index of crest development (head height/body height). In females the swelling of the belly, an indicator of the degree of ripeness, was also classified on an ordinal scale of 0 to 3 .

As data did not conform to the assumptions of parametric tests, non-parametric procedures were applied. Unless noted otherwise Wilcoxon signed-rank tests were applied. All tests were two-tailed.

\section{Results}

Females were sequentially presented to the same pair of males with and without the glass partition. Sixteen of the 20 females consistently associated with the same male during the first and the second step of the experiment $\left(\chi^{2}=7.20, d f=1, P=0.007\right)$. The remaining four females did not court or spawn with any of the males and were excluded from the analysis.

During step 1 of the experiment, only one female did not spend more time close to the male that received more courtship displays during step $2\left(\chi^{2}=12.25, d f=1\right.$, $P<0.000)$ and the average time previously spent by females close to this male was also significantly higher $(z=2.90 ; n=16 ; P=0.004$; Fig. 2$)$. These results demonstrate a consistency between the two measures of

Table 1 Comparison of the measured traits between the male that females preferred to associate with and the non-preferred male $(n=16)$ and between the male that females spawned with and the

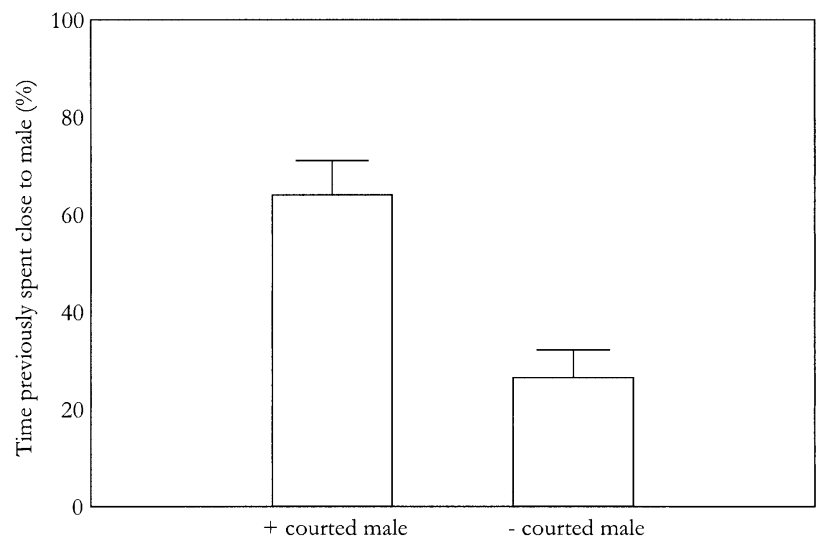

Fig. 2 Time previously spent by females close to the male that subsequently received more courtship displays and fewer courtship displays $(n=16)$. Bars mean; whiskers SE

preference recorded: time spent close to the male and courtship displays directed towards the male.

Females preferred to associate with and to court the male that had the larger head crest (Table 1). No difference in body size or in the development of the anal gland was recorded between preferred and non-preferred males (Table 1).

Nine females spawned, always with only one of the males. Four females laid eggs during the 1 st day and five during the 2nd day. Both measures of female preference failed to predict matings. During step 1 of the experiment females did not spend more time close to the male with whom they subsequently spawned $(z=0.47 ; n=9$; $P=0.636$ ), and during step 2 , this male did not receive more courtship displays $(z=0.53 ; n=9 ; P=0.594)$. No difference was recorded in any of the measured traits between the male that received eggs and the male that did not receive eggs (Table 1).

Females that spawned were larger than females that did not spawn and had more-distended bellies (Table 2). Four females spawned with the male that they had male that did not receive eggs $(n=9)$. Values are mean \pm SE. Wilcoxon signed-rank tests were applied to analyse differences

\begin{tabular}{|c|c|c|c|c|c|c|c|c|}
\hline & $\begin{array}{l}\text { Preferred } \\
\text { male }\end{array}$ & $\begin{array}{l}\text { Non-preferred } \\
\text { male }\end{array}$ & $Z$ & $P$ & $\begin{array}{l}\text { Male that } \\
\text { received eggs }\end{array}$ & $\begin{array}{l}\text { Male that did } \\
\text { not receive eggs }\end{array}$ & $z$ & $P$ \\
\hline Standard length $(\mathrm{cm})$ & $9.83 \pm 0.22$ & $9.94 \pm 0.34$ & 0.39 & 0.698 & $10.21 \pm 0.52$ & $9.70 \pm 0.38$ & 1.60 & 0.110 \\
\hline Anal gland development $(0-3)$ & $2.69 \pm 0.12$ & $2.81 \pm 0.10$ & 0.63 & 0.529 & $2.55 \pm 0.18$ & $2.89 \pm 0.11$ & 1.21 & 0.22 \\
\hline
\end{tabular}

Table 2 Comparison of the standard length and degree of belly swelling between females that spawned $(n=9)$ and females that did not spawn $(n=7)$. Values are mean \pm SE.

Mann-Whitney tests were applied to analyse differences

\begin{tabular}{lllll}
\hline & Females that spawned & Females that did not spawn & $z$ & $P$ \\
\hline Standard length $(\mathrm{cm})$ & $6.37 \pm 0.24$ & $5.60 \pm 0.25$ & -1.91 & 0.057 \\
Belly swelling $(0-3)$ & $2.00 \pm 0.00$ & $1.57 \pm 0.07$ & -3.40 & 0.000 \\
\hline
\end{tabular}


previously spent more time close to. These females had more-swollen bellies in comparison with the five females that spawned with the previously less preferred male (Mann-Whitney test: $z=-2.11 ; P=0.034)$. No difference in standard length was detected between these two groups of females (Mann-Whitney: $z=-0.98 ; P=0.324$ ).

\section{Discussion}

Females consistently associated with the same male during the two sequential steps of the experiment and the preferred male had, on average, a more developed crest, demonstrating that female association with a particular male was not arbitrary.

The male with whom females preferred to associate during the first step of the experiment was also the male that subsequently received more courtship displays. This association between the two measures of female preference, time spent close to a male and courtship displays directed towards that male, validates the use of the former as an indicator of female mate preference in future experiments.

Previous laboratory studies have shown that the development of the male's crest correlates with the time spent by females courting a male (Gonçalves et al. 2002b) and with the number of eggs received by males (E. Barata, personal communication). Corroborating these results, in our experiment females preferred to associate and directed more courtship displays towards the male that had the larger crest. In the field, however, no relation between the development of the crest and the male's reproductive success has been demonstrated to date (Oliveira et al. 1999; Gonçalves et al. 2002a). These results suggest a female preference towards males with more developed crests, although in the field male choosiness and male-male competition for nest sites, with larger males having a higher reproductive success (Oliveira et al. 1999; Gonçalves et al. 2002a), probably dilutes the effect of this preference.

In our experiment successful males were not larger than unsuccessful males. This result may be explained by the small difference in size in paired males (mean difference: $0.7 \mathrm{~cm}$; range: $0.1-1.8 \mathrm{~cm}$ ), which could have made the assessment of males' size difference by females difficult. Alternatively, larger males can have a higher reproductive success in the field due to their advantage in male-male competition for the access to nests (as demonstrated for many species, e.g. Pomatoschistus minutus, Magnhagen and Kvarnemo 1989) and not to female preference for larger males.

Both measures of preference failed to predict with which of the males females would subsequently spawn. Female mate choice depends on female preferences but also on mate sampling costs and male choosiness (Jennions and Petrie 1997). In this population of S. pavo, females have the most active role in courtship and males are the choosier sex (Almada et al. 1994). Both in the field and in captivity males often reject courting females
(Almada et al. 1995; D. Gonçalves, personal observations). In our experiment males frequently attacked females during the second observational period, and it is likely that some of the females had to mate with the less preferred male. The fact that seven females did not spawn with any of the males, in spite of courting at least one of them, could indicate that these females were rejected by both males.

Females that spawned had more-distended bellies, which could indicate either a higher motivation to spawn, or that males preferred to mate with these females. Corroborating this last hypothesis, females that spawned with the previously preferred male had more-swollen bellies than females that spawned with the previously non-preferred male.

Females that spawned were larger than females that did not spawn, probably reflecting male preference for larger females. Larger females with more distended bellies are likely to have a higher fecundity and previous studies in other species have demonstrated male preference for larger females [e.g. threespine stickleback, Gasterosteus aculeatus L., Rowland 1982; Sargent et al. 1986; Jamaican beaugregory damselfish, Stegastes leucostictus (Müller and Troschel), Itzkowitz et al. 1998] and for females with more developed bellies (e.g. G. aculeatus, Rowland 1982, 1989).

In this population, small males cannot compete with large males for the access to nests and reproduce as sneakers (Gonçalves et al. 1996). Sneakers resemble females morphologically and approach nesting males imitating the female's courtship behaviour to achieve parasitic fertilizations of the eggs (Gonçalves et al. 1996). Thus, males can also reject small females with lessdistended bellies because they can potentially be confounded with sneakers. During the breeding season females have bellies significantly more distended than sneakers and sneakers larger than 6-8 cm start to develop male secondary sexual ornaments (D. Gonçalves, T. Fagundes, and R. Oliveira, unpublished data). Thus, a male can benefit by choosing to mate with a large and round female not only because it will potentially receive more or larger eggs, but also because it may decrease the risk of parasitic fertilizations by sneakers.

In conclusion, we found a congruence between the two proximate measures of female preference used, validating "time spent close to a sexual partner" as a measure of female preference in $S$. pavo. Future sexual selection studies on this species may benefit from this result, using this easy-to-measure variable to evaluate female preference for male traits.

Both measures of female preference failed to predict matings, probably because in this population males are the choosy sex, often rejecting courting females. We argue that matings may not accurately indicate female preferences in sex-role-reversed species and male preferences in species with traditional sex roles. In the first case, males may reject females and force them to mate with a less preferred male and in the latter males may be rejected by females. 
Acknowledgements We acknowledge the Ria Formosa Nature Park for providing essential logistical and technical support. During this study D.M.G. was funded by a PRAXIS XXI Ph.D. grant (BD/ 13436/97).

\section{References}

Almada VC, Gonçalves EJ, Santos AJ, Baptista C (1994) Breeding ecology and nest aggregations in a population of Salaria pavo (Pisces: Blenniidae) in an area where nest sites are very scarce. J Fish Biol 45:819-830

Almada VC, Gonçalves EJ, Oliveira RF, Santos AJ (1995) Courting females: ecological constraints affect sex roles in a natural population of the blenniid fish, Salaria pavo. Anim Behav 49:1125-1127

Andersson M (1994) Sexual selection. Princeton University Press, Princeton, N.J.

Basolo AC (1990) Female preference for male sword length in the green swordtail, Xiphophorus helleri (Pisces: Poecilidae). Anim Behav 40:332-338

Berglund A, Rosenqvist G, Svensson I (1986) Mate choice, fecundity and sexual dimorphism in two pipefish species (Synganthidae). Behav Ecol Sociobiol 19:301-307

Couldridge VCK, Alexander GJ (2001) Does the time spent near a male predict female mate choice in a Malawian cichlid? J Fish Biol 59:667-672

Darwin C (1859) On the origin of species by means of natural selection. Murray, London

Darwin C (1871) The descent of man, and selection in relation to sex. Murray, London

Fishelson L (1963) Observations on littoral fishes of Israel I. Behaviour of Blennius pavo Risso (Teleostei: Blenniidae). Isr J Zool 12:67-80

Forsgren E (1992) Predation risk affects mate choice in a gobiid fish. Am Nat 140:1041-1049

Gonçalves D, Simões PC, Chumbinho AC, Correia MJ, Fagundes T, Oliveira RF (2002a) Fluctuating asymmetries and reproductive success in the peacock blenny, Salaria pavo (Risso). J Fish Biol 60:810-820

Gonçalves DM, Barata EN, Oliveira RF, Canário AVM (2002b) The role of male visual and chemical cues on the activation of female courtship behaviour in the sex-role reversed peacock blenny. J Fish Biol 61:96-105

Gonçalves EJ, Almada VC, Oliveira RF, Santos AJ (1996) Female mimicry as a mating tactic in males of the blenniid fish Salaria pavo. J Mar Biol Assoc UK 76:529-538

Itzkowitz M, Draud MJ, Barnes JL, Haley M (1998) Does it matter that male beaugregory damselfish have a mate preference? Behav Ecol Sociobiol 42:149-155

Jennions MD, Petrie M (1997) Variation in mate choice and mating preferences: a review of causes and consequences. Biol Rev $72: 283-327$
Kodric-Brown A (1985) Female preference and sexual selection for male coloration in the guppy (Poecilia reticulata). Behav Ecol Sociobiol 17:199-205

Kodric-Brown A, Nicoletto PF (1997) Repeatability of female choice in the guppy: response to live and videotaped males. Anim Behav 54:369-376

Landmann K, Parzefall J, Schlupp I (1999) A sexual preference in the Amazon molly, Poecilia formosa. Environ Biol Fish $56: 325-331$

Magnhagen C, Kvarnemo C (1989) Big is better: the importance of size for reproductive success in male Pomatoschistus minutus (Pallas) (Pisces: Gobiidae). J Fish Biol 35:755-763

Milinski M, Baker TCM (1990) Female sticklebacks use male coloration in mate choice and hence avoid parasitized males. Nature 344:330-333

Oliveira RF, Almada VC, Forsgren E, Gonçalves EJ (1999) Temporal variation in male traits, nest aggregations and mating success in the peacock blenny, Salaria pavo. J Fish Biol $54: 499-512$

Papaconstantinou CA (1979) Secondary sex characters of blennioid fishes (Pisces: Blenniidae). Thalassographica 1:57-75

Patzner RA, Seiwald M (1987) The reproduction of Blennius pavo II. Secondary sexual organs and accessory glands of the testis during the reproductive cycle. In: Kullander S, Fernholm B (eds) Proceedings of the V congress of European ichthyologists. Swedish Museum of Natural History, Stockholm, pp 293-298

Patzner RA, Seiwald M, Adlgasser M, Kaurin G (1986) The reproduction of Blennius pavo $\mathrm{V}$. Reproductive behaviour in natural environment. Zool Anz 216:338-350

Rosenqvist G (1990) Male mate choice and female-female competition for mates in the pipefish Nerophis ophidion. Anim Behav 39:1110-1115

Rowland WJ (1982) Mate choice by male sticklebacks. Anim Behav 30:1093-1098

Rowland WJ (1989) The ethological basis of mate choice in male threespine sticklebacks, Gasterosteus aculeatus. Anim Behav 38:112-120

Ryan MJ, Hews DK, Wagner WE Jr (1990) Sexual selection on alleles that determine body size in the swordtail Xiphophorus nigrensis. Behav Ecol Sociobiol 26:231-237

Sargent RC, Gross MR, Bergh EP van den (1986) Male mate choice in fishes. Anim Behav 34:545-550

Schlupp I, Marler C, Ryan MJ (1994) Benefit to male sailfin mollies of mating with heterospecific females. Science 263:373-374

Vagelli A (1999) The reproductive biology and early ontogeny of the mouthbrooding banggai cardinalfish, Pterapogon kauderni (Perciformes, Apogonidae). Environ Biol Fish 56:79-92

Zander CD (1986) Blenniidae. In: Whitehead PJP, Bauchot ML, Hureau JC, Nielsen J, Tortonese E (eds) Fishes on the northeastern Atlantic and the Mediterranean. Unesco, Paris, pp 1096-1112 